Open Access

\title{
Suicidal behaviors among Moroccan school students: prevalence and association with socio-demographic characteristics and psychoactive substances use: a cross- sectional study
}

Btissame Zarrouq ${ }^{1,2,6^{*}}$, B. Bendaou ${ }^{1,2}$, S. Elkinany ${ }^{5}$, I. Rammouz ${ }^{3}$, R. Aalouane ${ }^{3}$, B. Lyoussi ${ }^{2}$, S. Khelafa ${ }^{4}$, A. Bout ${ }^{4}$, N. Berhili ${ }^{4}$, H. Hlal ${ }^{4}$, C. Nejjari ${ }^{1}$ and K. El Rhazi ${ }^{1}$

\begin{abstract}
Background: Suicidal behavior is a major cause of injury and death worldwide, especially among adolescents and young adults. Few studies have tackled this issue in the Arab world. The present study investigated the prevalence and the risk factors of suicidal behaviors among Moroccan school students.

Methods: From April 2012 to November 2013, a cross-sectional study was conducted in the North-Centre region of Morocco among students in public secondary schools selected using stratified cluster random sampling. The data were collected via anonymous self-administered questionnaires. The Mini International Neuropsychiatric Interview was used in its Moroccan Colloquial Arabic version to assess suicidality according to the DSM-IV criteria.
\end{abstract}

Results: A total of 3020 students (53\% boys) aged 11-23 years (average age $=16 \pm 2.1$ years) were included in the study. The prevalence of suicide ideation, suicide planning and suicide attempts during the last month were 15.7, 6.3 , and $6.5 \%$ respectively.

Univariate analyses demonstrated that suicidal behaviors followed different epidemiological patterns. According to the multivariate analyses, the risk factors for all suicidal behaviors among Moroccan school students were the female gender, middle school level, urban locations, low family income, parents' divorce, tobacco consumption and psychoactive substances (alcohol and cannabis) use.

Conclusions: The intervention of preventive programs has become an emergency to overcome the issue of suicidality in Morocco. Further researches on adolescents' suicidal behaviors are suggested to update temporal data and assess the effectiveness of potential interventions.

Keywords: Suicidal behavior, Suicide ideation, Suicide plan, Suicide attempts, Psychoactive substances use, Tobacco use, School students, Morocco

\footnotetext{
*Correspondence: btissame.zarrouq@usmba.ac.ma

'Laboratory of Epidemiology, Clinical Research, and Health Community,

Faculty of Medicine and Pharmacy, Sidi Mohammed Ben Abdallah University,

Fez, Morocco

${ }^{2}$ Laboratory of Physiology-Pharmacology and Environmental Health, Dhar El

Mahraz Faculty of Sciences, Sidi Mohammed Ben Abdallah University, Fez,

Morocco

Full list of author information is available at the end of the article
}

() Biomed Central

(c) 2015 Zarrouq et al. Open Access This article is distributed under the terms of the Creative Commons Attribution 4.0 International License (http://creativecommons.org/licenses/by/4.0/), which permits unrestricted use, distribution, and reproduction in any medium, provided you give appropriate credit to the original author(s) and the source, provide a link to the Creative Commons license, and indicate if changes were made. The Creative Commons Public Domain Dedication waiver (http://creativecommons.org/publicdomain/zero/1.0/) applies to the data made available in this article, unless otherwise stated. 


\section{Background}

Suicidal behavior comprises a wide range of thoughts and acts intended to end one's life, such as suicidal ideation, suicide planning, and suicide attempts [1]. Suicidal ideation refers to thoughts of engaging in behavior intended to end one's life, whereas suicide planning is defined as the formulation of a specific method through which one intends to die. Finally, attempted suicide is understood as an engagement in potentially self-injurious behavior in which there is at least some intent to die [2, 3].

Suicidal behaviors are among the main causes of death worldwide, especially among adolescents and young adults $[4,5]$. It is estimated that for every suicide that occurs worldwide, there are up to 20 suicide attempts [6]. According to the World Health Organization report (2014), the global median rate of suicide was 6.55 per 100000 people, compared to 4.90 in the countries of the Eastern Mediterranean Region [6].

Based on the previous findings, suicide may not seem as one of the most urgent health problems in this region. In fact, suicides simply die uncounted in countries without reliable registration of deaths [6]. Moreover, in some countries of the Eastern Mediterranean Region, such as Morocco, there is no national register for suicide. The only reported suicide deaths are the ones which occur inside Moroccan hospitals. Other suicide deaths may often be misclassified as an accident or another cause of death to avoid familial, religious, and social stigmatizations. Given the fact that suicide and attempted suicide are considered disgraceful acts prohibited by religion, condemned by society, and hampered by legal consequences, suicidality remains a taboo in this region of the world [7].

As a matter of fact, the epidemiological studies investigating the prevalence of suicidal behaviors and their correlates are scarce. In Morocco; for instance, only one survey was conducted among the general population, based on face-to-face household interviews. The results showed that the prevalence of suicide attempts and suicidal ideation during one month were 2.1 and $6.3 \%$, respectively [8]. The Global School Health Survey (GSHS) conducted by the World Health Organization, in collaboration with the US Centers for Disease Control and Prevention, provided an important opportunity to rectify the lack of data on youth suicidal behavior. The GSHS conducted in 2010 among Moroccan school students aged 13-15, showed that the past 12 month prevalence of suicide ideation ranged from 13.3 to $18.4 \%$; while, suicide attempts reached $13.3 \%$ [9].

Concerning the risk factors of youth suicidal behaviors, the most frequently reported ones were mental health problems, alcohol as well as psychoactive substances (PASs) use, and poor familial or social bonds [10-12].

Obviously, the data on the issue of Moroccan youth suicidality are rare. Henceforth, the presented study aimed at determining the prevalence and the correlates of suicidal behaviors among school students in the NorthCentre of Morocco.

\section{Methods \\ Research design}

This cross-sectional study was conducted from April 2012 to November 2013 (Additional file 1). The project was approved by the Ethics Committee of the Faculty of Medicine and pharmacy of Sidi Mohammed Ben Abdellah University. The participants were students from middle and high public schools in the North Central Region of Morocco (namely regions of Fez, Boulemane, Taza, Tawnat, and Hoceima). Based on the lists of schools in this region, which were obtained from the Statistical Office of National Education Ministry, schools were split into seven geographic regions, and classified into two strata: urban and rural. The stratified random sampling was carried out according to the type of schools (middle or high school) using the proportional allocation technique, that is to divide the sample in each stratum (urban and rural) based on the proportionality of middle and high schools depending on the total number of schools. Eventually, 44 middle schools and 24 high schools were randomly selected. Indeed, all the students from the selected classes were included in the study. The questionnaires (Additional file 2) were administered upon receiving school-directors permissions and verbal informed consents from all participants. Concerning the students under the age of 16, verbal informed consents from the parents were also obtained. The process of contacting parents was facilitated through parents' associations.

Trained resident doctors on psychiatry distributed the questionnaires in the classrooms during a regular class period. The questionnaires' instructions stated that participation was voluntary and that responses were anonymous and confidential.

\section{Assessment \\ Socio-demographic characteristics}

A questionnaire was used to collect demographic information such as age, gender, educational level, family income, parents' marital status and their educational levels.

\section{Suicidal behavior}

To asses suicidal behavior according to the DSM-IV criteria [13], The Mini International Neuropsychiatric Interview (MINI) [14], was used in its Moroccan Colloquial Arabic version [15]. THE MINI suicidality module involved 6 items; each one consisted of a dichotomous response type (Yes/No), and all questions were relevant to suicidal behaviors including death wish, self-harm wish, suicide ideation, suicide plan, suicide attempt in the past month, and lifetime suicide attempts. 


\section{Psychoactive substances use}

As stated in the report of the Mediterranean School Project on Alcohol and Other Drugs, the most used substance among Moroccan school students was tobacco, followed by alcohol, then cannabis [16]. Thus, each respondent in this study was asked on his or her tobacco, alcohol, and cannabis use during their lifetime. The types of smoking habits were determined according to the International Union against Tuberculosis and Lung Diseases guide [17]. Moreover, a lifetime psychoactive substances use (alcohol and cannabis use) was considered in case of the consumption of these psychoactive substances at least once in the lifetime.

\section{Statistical analyses}

The data entry stage started immediately after data collection. Data were entered into MS Windows Excel in the form of codes, and transferred to the Statistical Package for Social Sciences (SPSS) software version 20 (SPSS Inc., Chicago, IL, USA). Data analysis involved descriptive as well as inferential statistics. A simple descriptive analysis was done for the variables of interest. Prevalence with $95 \%$ confidence intervals $(95 \% \mathrm{CI})$ was also estimated. Odds ratios, along with $95 \%$ confidence intervals, were calculated. Differences in proportions were assessed by the Chi-square test. $P$ values of $<0.05$ were considered as statistically significant.

\section{Results}

\section{Socio-demographic characteristics}

Out of 3170 students who participated in the study, 3020 completed the questionnaires (response rate $=95.2 \%$ ). There were more males (53\%) than females (47\%), and the average age was 16 years ( $\mathrm{SD}=2.1$ years). Other sociodemographic characteristics of the sample were displayed in Table 1.

\section{Psychoactive substances use}

As showed in Table 1, the prevalence of current smokers was $9.1 \%$ (95 \% CI: $8.1 \%-10.2 \%)$. Male students were more likely to smoke cigarettes than females $(15 \%$ vs. $2.5 \% ; p<0.001)$. As for psychoactive substances consumption, the overall lifetime prevalence was $9.4 \%$ (95\% CI: $8.35 \%-10.47 \%)$. Likewise, the rate of psychoactive substances use was higher among boys than girls (15.74\% vs. $2.13 \% ; p<0.001)$. Cannabis recorded the highest lifetime prevalence with $8.08 \%$ (13.53 among boys vs. 1.92 among girls), followed by alcohol $4.31 \%$ (7.49 among boys vs. 0.71 among girls).

\section{Prevalence of suicidal behaviors}

The most prevalent suicidal behavior during the last month among the studied sample was death wish (26.6\%), followed by suicide ideation (15.7\%), and self-harm wish
(14.7\%). Concerning the suicide attempts which occurred in the last month (6.5\%), the majority were planned (6.3\%). Life time suicide attempts on the other hand reached $10.5 \%$ (Table 2 ).

\section{Correlations of socio-demographic characteristics and suicidal behaviors}

The female gender was the only socio-demographic variable which displayed significant association with all suicidal behaviors. For the other socio-demographic characteristics, suicidal behaviors followed various epidemiological patterns as illustrated in Table 3.

\section{Suicidal behaviors in smokers and psychoactive substances (PASs) users}

The prevalence of suicide ideation, planning and attempts during the last month among cigarettes smokers was 25.1, 10.9 , and $12.2 \%$, respectively. Among PASs users, the prevalence was $26.7,14.9$, and $16.5 \%$, respectively. Upon comparing suicidality based on tobacco and PASs use status, all suicidal behaviors were highly detected among smokers and users of PASs conversely to non-smokers and non-users, as shown in Table 4.

\section{Multivariate analysis}

The binary logistic regression confirmed that suicidal behaviors did not follow the same epidemiological patterns. On the whole, socio-demographic risk factors for all suicidal behaviors among Moroccan school students were: the female gender, low family income, middle school level, urban locations, parents' divorce. Parents' educational level and parents' employment however exhibited statistically non-significant association.

For the association of suicidal behaviors with tobacco and PASs use, the results showed that current smoking $(\mathrm{OR}=2.7, p<0.0001)$ was more associated with suicidal ideation than PASs use $(\mathrm{OR}=1.8, p=0.004)$; while, lifetime alcohol use and cannabis consumption $(\mathrm{OR}=3.6$, $p<0.0001)$ were more associated with past month suicide attempts than tobacco use $(\mathrm{OR}=1.9, p=0.007)$.

\section{Discussion}

The present study aimed at determining the prevalence and the risk factors of suicidal behaviors mainly suicide ideation, suicide planning, and suicide attempts among Moroccan school students. Regarding suicide ideation, the prevalence was $15 \%$ in subjects aged 13 to 15 years, which was almost identical to the national prevalence (15.7 \%) reported by the 2010 Morocco GSHS [9]. The reported prevalence in Morocco was indeed similar to the GSHS results in other Arab countries, (15\%) in Lebanon in 2011, and (15.5 \%) in United Arab Emirates in 2010; while, it was lower than the GSHS findings in Tunisia in 2008 (19.8 \%) and in Mauritania in 2010 
Table 1 Sample characteristics $(N=3020)$

\begin{tabular}{|c|c|c|}
\hline Characteristics & Number & Percent \\
\hline \multicolumn{3}{|l|}{ Gender } \\
\hline Boys & 1602 & 53 \\
\hline Girls & 1418 & 47 \\
\hline \multicolumn{3}{|l|}{ Age group } \\
\hline $11-14$ & 795 & 26.4 \\
\hline $15-18$ & 1857 & 61.7 \\
\hline $19-23$ & 357 & 11.9 \\
\hline \multicolumn{3}{|l|}{ School level } \\
\hline Middle school & 1657 & 54.9 \\
\hline High school & 1363 & 45.1 \\
\hline \multicolumn{3}{|l|}{ School location } \\
\hline Urban & 2273 & 75.3 \\
\hline Rural & 774 & 24.7 \\
\hline \multicolumn{3}{|l|}{ Parents' marital status } \\
\hline Married & 2684 & 89.3 \\
\hline Divorced & 109 & 3.7 \\
\hline Widowed & 145 & 4.9 \\
\hline Separated & 65 & 2.1 \\
\hline \multicolumn{3}{|l|}{ Father education } \\
\hline Illiterate & 1065 & 35.9 \\
\hline Primary & 806 & 27.2 \\
\hline Secondary & 767 & 25.9 \\
\hline University and above & 326 & 11 \\
\hline \multicolumn{3}{|l|}{ Mother education } \\
\hline Illiterate & 1813 & 60.6 \\
\hline Primary & 514 & 17.2 \\
\hline Secondary & 517 & 17.3 \\
\hline University and above & 149 & 5 \\
\hline \multicolumn{3}{|l|}{ Father employment } \\
\hline Employed & 2490 & 88.4 \\
\hline Unemployed & 82 & 2.9 \\
\hline Retired & 245 & 8.7 \\
\hline \multicolumn{3}{|l|}{ Mother employment } \\
\hline Employed & 281 & 9.5 \\
\hline Unemployed & 2688 & 90.5 \\
\hline \multicolumn{3}{|l|}{ Family income } \\
\hline$\leq 300 £$ & 498 & 16.8 \\
\hline $301-1000 £$ & 2280 & 76.9 \\
\hline$\geq 1000 £$ & 187 & 6.3 \\
\hline \multicolumn{3}{|l|}{ Smoking } \\
\hline Non smokers & 2532 & 83.9 \\
\hline Current smokers & 275 & 9.1 \\
\hline Ex-smokers & 210 & 7.0 \\
\hline
\end{tabular}

Table 1 Sample characteristics $(N=3020)$ (Continued)

\begin{tabular}{lll}
\hline Lifetime PASs use & & \\
No & 2713 & 90.6 \\
Yes & 280 & 9.4 \\
\hline
\end{tabular}

(31.1\%) [18]. Contrariwise, the overall prevalence of suicide ideation among Moroccan school students was among the lowest in comparison with other African countries (Benin, Ghana, Kenya, Zambia), some countries in the Americas (Chile, Guyana, and Santa Lucia), some European and Asiatic countries (Austria, Turkey, China), in which suicidal ideation was found to be very common among youth (up to $44 \%$ among high school students) [18-20].

Concerning suicide attempts, it was demonstrated that the lifetime prevalence of these attempts among Moroccan school students $(10.5 \%)$ was seemingly equivalent to the average global rate $(9.7 \%)$ as reported in a systematic review from the international literature on the prevalence of suicidal phenomena among 513,188 adolescents in 2005 [21]. Nevertheless, the self-reported lifetime prevalence of suicide attempts in the present study (10.5\%) proved high in comparison with American and European countries. According to a recent survey conducted among 6483 American adolescents in 2013, the estimated lifetime prevalence of suicide attempts was $4.1 \%$ [22]. Indeed, the Saving and Empowering Young Lives in Europe (SEYLE) project (2014), conducted across 11 European countries, revealed that $4.2 \%$ adolescents attempted suicide during their lifetime [23].

The previous findings are surprising, in the sense that the prevalence of suicide ideation was low; while, the prevalence of suicide attempts proved high compared with western countries.

In essence, any comparison with western countries should be interpreted with caution due to the methodological

Table 2 Prevalence of suicidal behaviors among Moroccan school students

\begin{tabular}{|c|c|c|c|}
\hline Suicidal behaviors & Number & Percent & $95 \% \mathrm{Cl}$ \\
\hline \multicolumn{4}{|l|}{ In the past month, did you } \\
\hline $\begin{array}{l}\text { Think that you would be better off } \\
\text { dead or wish you were dead? (Yes) }\end{array}$ & 768 & 26.6 & $25-28.2$ \\
\hline Want to harm yourself? (Yes) & 426 & 14.7 & $13.5-16.1$ \\
\hline Think about suicide? (Yes) & 453 & 15.7 & $14.4-17.1$ \\
\hline Have a suicide plan? (Yes) & 182 & 6.3 & $5.4-7.2$ \\
\hline Attempt suicide? (Yes) & 187 & 6.5 & $5.6-7.4$ \\
\hline \multicolumn{4}{|l|}{ In your life } \\
\hline $\begin{array}{l}\text { Did you ever make a suicide } \\
\text { attempt? (Yes) }\end{array}$ & 304 & 10.5 & $9.4-11.7$ \\
\hline
\end{tabular}


Table 3 Socio-demographic characteristics and their correlations with suicidal behaviors among Moroccan school students

\begin{tabular}{|c|c|c|c|c|c|c|c|c|c|c|c|c|}
\hline & \multicolumn{2}{|c|}{$\begin{array}{l}\text { Past month } \\
\text { death wish }\end{array}$} & \multicolumn{2}{|c|}{$\begin{array}{l}\text { Past month } \\
\text { self-harm wish }\end{array}$} & \multicolumn{2}{|c|}{$\begin{array}{l}\text { Past month } \\
\text { suicide ideation }\end{array}$} & \multicolumn{2}{|c|}{$\begin{array}{l}\text { Past month } \\
\text { suicide plan }\end{array}$} & \multicolumn{2}{|c|}{$\begin{array}{l}\text { Past month } \\
\text { suicide attempt }\end{array}$} & \multicolumn{2}{|c|}{$\begin{array}{l}\text { Lifetime suicide } \\
\text { attempts }\end{array}$} \\
\hline & (\%) & $P$ value & (\%) & $P$ value & $(\%)$ & $P$ value & (\%) & $P$ value & $(\%)$ & $P$ value & $(\%)$ & $P$ value \\
\hline Gender & & $<0.0001$ & & $<0.001$ & & $<0.0001$ & & 0.004 & & 0.02 & & $<0.0001$ \\
\hline Boys & 17.5 & & 12.6 & & 10.9 & & 5.1 & & 5.5 & & 7.8 & \\
\hline Girls & 36.8 & & 17.1 & & 20.9 & & 7.6 & & 7.4 & & 13.5 & \\
\hline Age (years) & & 0.003 & & 0.03 & & 0.04 & & 0.3 & & 0.7 & & 0.1 \\
\hline $11-14$ & 22.3 & & 12 & & 12.8 & & 6.5 & & 6.7 & & 10.8 & \\
\hline $15-18$ & 28.8 & & 15.9 & & 16.6 & & 6.5 & & 6.5 & & 10.9 & \\
\hline $19-23$ & 25.4 & & 14.7 & & 17.1 & & 4.4 & & 5.6 & & 7.6 & \\
\hline School level & & 0.009 & & 0.2 & & 0.3 & & $<0.0001$ & & $<0.0001$ & & 0.001 \\
\hline Middle school & 24.8 & & 15.2 & & 15.4 & & 7.7 & & 7.9 & & 12.2 & \\
\hline High school & 28.8 & & 14.3 & & 16.1 & & 4.6 & & 4.7 & & 8.5 & \\
\hline School location & & $<0.0001$ & & 0.01 & & $<0.0001$ & & 0.06 & & 0.1 & & 0.03 \\
\hline Rural & 20.4 & & 12.3 & & 11.1 & & 5 & & 5.6 & & 8.7 & \\
\hline Urban & 28.7 & & 15.6 & & 17.3 & & 6.7 & & 6.8 & & 11.2 & \\
\hline Parents' marital status & & $<0.0001$ & & 0.007 & & 0.001 & & 0.01 & & $<0.0001$ & & 0.1 \\
\hline Married & 25.4 & & 14 & & 14.9 & & 5.8 & & 5.9 & & 10.2 & \\
\hline Divorced & 37.7 & & 22.6 & & 24.8 & & 13.2 & & 16 & & 15.1 & \\
\hline Widowed & 33.3 & & 17.4 & & 15.9 & & 8 & & 8.7 & & 13.1 & \\
\hline Separated & 45.2 & & 24.2 & & 30.6 & & 9.7 & & 8.1 & & 9.7 & \\
\hline Father education & & 0.016 & & 0.004 & & 0.01 & & 0.1 & & 0.006 & & 0.4 \\
\hline Illiterate & 25.6 & & 13.7 & & 14.2 & & 5.8 & & 6.4 & & 9.8 & \\
\hline Primary & 27 & & 15.4 & & 15.9 & & 5.7 & & 5.9 & & 11.4 & \\
\hline Secondary & 30 & & 17.5 & & 19.1 & & 8 & & 8.5 & & 11.4 & \\
\hline University and above & 20.8 & & 9.3 & & 12.2 & & 4.5 & & 2.9 & & 8.6 & \\
\hline Mother education & & 0.07 & & 0.1 & & 0.2 & & 0.9 & & 0.03 & & 0.07 \\
\hline Illiterate & 26.2 & & 14.9 & & 15 & & 6 & & 6.7 & & 10.5 & \\
\hline Primeray & 24.5 & & 12.7 & & 14.5 & & 6.2 & & 4 & & 8.4 & \\
\hline Secondary & 31 & & 16.5 & & 18.5 & & 6.8 & & 7.8 & & 13.1 & \\
\hline University and above & 23.4 & & 9.9 & & 14.2 & & 5.7 & & 3.5 & & 7.7 & \\
\hline Father employment & & 0.3 & & 0.06 & & 0.2 & & 0.1 & & 0.2 & & 0.06 \\
\hline Unemployed & 33.3 & & 22.2 & & 22.2 & & 11.1 & & 8.6 & & 12.3 & \\
\hline Employed & 26.2 & & 14.2 & & 15.5 & & 6.1 & & 6.5 & & 10.9 & \\
\hline Retired & 25.3 & & 17.2 & & 14.6 & & 5.2 & & 4.3 & & 6 & \\
\hline Mother employment & & 0.07 & & 0.1 & & 0.01 & & 0.1 & & 0.07 & & 0.09 \\
\hline Employed & 30.5 & & 16.8 & & 15 & & 8.2 & & 8.6 & & 13.1 & \\
\hline Unemployed & 26.2 & & 14.3 & & 20.5 & & 6 & & 6.1 & & 10.2 & \\
\hline Family income & & $<0.0001$ & & $<0.0001$ & & $<0.0001$ & & 0.08 & & 0.001 & & 0.01 \\
\hline$\leq 300 £$ & 34.1 & & 22.8 & & 23.1 & & 8.4 & & 9.6 & & 13.9 & \\
\hline $301-1000 £$ & 25.1 & & 12.4 & & 14.1 & & 5.7 & & 5.4 & & 9.5 & \\
\hline$\geq 1000 £$ & 25 & & 18.1 & & 13.1 & & 5.7 & & 9.1 & & 12.4 & \\
\hline
\end{tabular}

differences present across suicide studies; therefore, it is difficult to make generalizations about the prevalence of suicidal behaviors.
To explain the previous contrast in the light of Moroccan culture specificities, suicide ideation low prevalence can be relegated to the religious and cultural prohibition of suicide, 
Table 4 Comparison of suicidal behaviors according to tobacco, and psychoactive substances use status

\begin{tabular}{|c|c|c|c|c|c|c|}
\hline & \multicolumn{2}{|l|}{ Tobacco } & \multirow[t]{2}{*}{$P$-value } & \multicolumn{2}{|c|}{ Psychoactive substances } & \multirow[t]{2}{*}{$P$-value } \\
\hline & $\begin{array}{l}\text { Smokers (\%) } \\
{[95 \% \mathrm{Cl}]}\end{array}$ & $\begin{array}{l}\text { Non-smokers (\%) } \\
{[95 \% \mathrm{Cl}]}\end{array}$ & & $\begin{array}{l}\text { Users (\%) } \\
{[95 \% \mathrm{Cl}]}\end{array}$ & $\begin{array}{l}\text { Non-users (\%) } \\
{[95 \% \mathrm{Cl}]}\end{array}$ & \\
\hline Death wish & $34.1[29.8-38.7]$ & $25.2[23.5-27]$ & $<0.001$ & $36.8[30.9-43.1]$ & $25.5[23.8-27.2]$ & $<0.001$ \\
\hline Self-harm wish & $27[23-31.4]$ & $12.4[11.1-13.8]$ & $<0.001$ & $31.7[26.1-37.8]$ & $13.1[11.8-14.4]$ & $<0.001$ \\
\hline Suicide ideation & $25.1[21.2-29.4]$ & 14 [12.6-15.4] & $<0.001$ & $26.7[21.4-32.6]$ & $14.7[13.3-16.1]$ & $<0.001$ \\
\hline Suicide plan & $10.9[8.2-14.2]$ & $5.4[4.6-6.4]$ & $<0.001$ & 14.9 [10.8-19.9] & $5.5[4.7-6.5]$ & $<0.001$ \\
\hline Suicide attempt in the past month & $12.2[9.4-15.6]$ & $5.4[4.5-6.4]$ & $<0.001$ & $16.5[12.1-21.6]$ & $5.5[4.7-6.5]$ & $<0.001$ \\
\hline Lifetime suicide attempts & 16.2 [13-20] & $9.5[8.3-10.7]$ & $<0.001$ & $19.6[14.9-25.1]$ & 9.6 [8.5-10.9] & $<0.001$ \\
\hline
\end{tabular}

or even suicide thoughts. To illustrate, Baasher argued that Islam was behind the low rates of suicidal behaviors recorded in Muslim communities [24]. In general terms, an expanding body of literature has thoroughly examined religiosity as a potential protective factor against the development and the persistence of mental disorders and risk behaviors among youth $[25,26]$.

Despite the fact that all participants in this study adhere to Islam, the lifetime prevalence of suicide attempts hints on youth non-conformist or deviant religious attitudes. Among the limitations of this study is unfortunately the absence of any question about religiosity degrees since there is no validated scale in Morocco developed to assess such a variable.

The high prevalence of suicide attempts can also be interpreted in relation to the ongoing economic and social changes occurring in the Moroccan society, which have created a growing rift between younger and older generations, and led to intensifying conflicts between Moroccan youth and the conservative society. Likewise, adults still perceive youth problems as superficial. Thus, suicide attempts could be a call for communication in a society that pays no heed to youth dilemmas. For this reason, medically non-serious suicide attempts are more common than medically serious ones. The present study, be it a community-based survey, tends to represent all suicidal attempts regardless of their severity degree. Generally speaking, medically non-serious suicide attempts are more reported than medically serious ones. For example, although $8.0 \%$ of United States students (grades 9 to 12) reported suicide attempts in the past year, the proportion reporting medically serious attempts- treated by a doctor or a nurse- was only $2.7 \%$ [27].

The most important characteristic of attempted and completed suicide is the extent to which the act was planned. In this study, $6.3 \%$ of students reported having made a suicide plan in the past month. For unplanned suicide attempts, the prevalence among Moroccan school students was unknown. Internationally, several studies revealed that the prevalence of unplanned or impulsive acts of suicide estimates has exceeded $50 \%$ among adolescents [28].

On the account of these alarming results, attention shifted towards the study of suicide risk factors. The obtained results showed that all suicidal behaviors were more common among girls than boys. Such findings were consistent with those reported internationally. Lewinsohn et al. found that the prevalence rates of suicide attempts are two to three times higher in females than in males [29]. Rezaeian using data from the World Health Organization Global Burden of Disease Project, reported that in the Eastern Mediterranean Region, the rates of suicide were higher in females than males in age groups 5-14 and 15-29 years [30]. Even for females aged 18-65, Weissman et al. noted that compared with males, females had higher rates of suicidal ideation and suicide attempts in nine countries (The United States, Canada, Puerto Rico, France, West Germany, Lebanon, Taiwan, Korea and New Zealand) [31]. Focusing on suicide attempts, the expression is mostly associated with genderspecific norms. Males for instance are more inclined towards risk-taking behaviors, and PASs use. Eventually, their suicide attempts are more likely to result in fatalities as they employ violent means and irreversible methods. Concerning females, gender specific norms, in conjunction with low social status and the lack of economic and personal power can result in more suicide ideation, rumination, depression, and nonfatal suicide attempts $[32,33]$. Suicide rates as matter of fact are typically higher in males than females, and the opposite for suicide attempts. This gender paradox was clarified in regards to genetic vulnerabilities and gender differences in early adverse environments, neurodevelopment, mental Disorder, social expectations and their complex interconnections [34].

In this study, an association was detected between tobacco consumption, PASs use, and suicidal behaviors. Current smoking was more associated with suicidal ideation and PASs consumption with suicide attempts. Such findings were consistent with other surveys depicting 
the consumption of tobacco and PASs as strong risk factors of suicidal behaviors [12, 35, 36]. Evren et al. and Juan et al. indicated a direct association between suicidal ideation and current smoking of cigarettes $[37,38]$. Likewise, drinking alcohol was directly associated with suicidal attempts. Certain characteristics of alcohol use appeared to be predictive of attempted suicide, such as high alcohol consumption, and the uptake of strong alcoholic drinks [39, 40]. Moreover, alcohol use could facilitate suicide attempts; it was observed that many subjects use some substance mostly alcohol before committing suicide [41]. Equally important, most longitudinal studies proved that early adolescent cannabis use increased the risk of later depression and suicidal behaviors [42-44]. In fact, the relationship between suicidal behaviors, tobacco and PASs is complicated. The association has been well established, yet causal links remain unclear because suicidal behaviors, tobacco and PASs use are multiply determined. To illustrate, the use of certain PASs alongside with suicidal behaviors are related with strong feelings of escapism $[45,46]$.

Similarly to our findings, previous studies on the potential risk factors of suicidal behaviors revealed that socioeconomic deprivation, poverty and stress or worry about the economic situation of the family were relevant correlates to suicidal behaviors among adolescents [47, 48]. The association between parents' cohabitation status and suicidal behaviors has already been investigated in many studies, and showed an indirect association between these two factors [39]. Family harmony on the other hand was found to have a stronger effect on reducing suicidal behaviors risk.

At last, the results of the present study should be considered in the light of several limitations. The study was based on a cross sectional sample, which indicated that the causal relations could not be determined. Indeed, despite of employing validated instruments to measure suicidality, the survey used self-reported data, which may reduce objectivity and introduce the possibility of misreporting. Furthermore, the sample consisting of school students cannot be considered as a representative sample of all Moroccan youth, because the study did not include unschooled teens. Finally, the study lacked data on characteristics such as mental disorders, parents' psychopathology, sexual abuse, and adverse childhood experiences; hence, the impact of these characteristics on suicidal behaviors could not be studied. Further research needs to be conducted in this regard.

Concerning the strengths of the present study, it included a large representative sample. It was the first study in kind to be performed among middle and high school students in the North Centre region of Morocco with the aim of investigating the prevalence and exploring the risk factors of suicidal behaviors.

\section{Conclusions}

Beyond these descriptive epidemiological results, an urgent intervention should be sought in favor of developing an integrated management approach to solve youth suicide problems. Since the findings of the current study have accentuated the pitfalls of youth mental health policies in Morocco, which do not consider the variations of suicidal behaviors depending on gender, PASs use status, and differences in socio-demographic characteristics. Even though suicidal ideation and suicidal attempts can be predictors of later suicide, the prediction of suicide remains very complex. There is therefore a need for the development of special prevention and intervention programs focusing on suicidal behaviors.

These prevention efforts need to be supported by parents and teachers who are supposed to pay more attention to adolescents' risky behaviors, bearing in mind that the latters can be a "cry for help". Further surveys on the suicidal behaviors of Moroccan adolescents are required to get temporal data and assess the effectiveness of future policies and interventions.

\section{Additional files}

Additional file 1: STROBE checklist for cross sectional studies. (DOC $88 \mathrm{~kb}$ )

Additional file 2: English version of the questionnaire. (DOCX $26 \mathrm{~kb}$ )

\section{Abbreviations}

GSHS: Global School Health Survey; PASs: psychoactive substances.

\section{Competing interests}

B. Zarrouq, B. Bendaou, S. Elkinany, I. Rammouz, R. Aalouane, S. Khlafa, A. Bout, N. Berhili, H. Hlal, B. Lyoussi, C. Nejjari and K. El Rhazi declare that they have no conflicts of interest.

\section{Authors' contributions}

BZ has contributed to the conception and the design of the study, the acquisition, the analysis, and the interpretation of data, and has been involved in drafting the manuscript; BB has contributed to the acquisition of data; SE has contributed to the acquisition of data, and has been involved in drafting and revising the manuscript; IR has contributed to the conception and the design of the study, and the acquisition of data; RA has contributed to the conception and the design of the study, and the acquisition of data; $\mathrm{BL}$ has contributed to the conception, and the design of the study; SK has contributed to the acquisition of data; $A B$ has contributed to the acquisition of data; NB has contributed to the acquisition of data; $\mathrm{HH}$ has contributed to the acquisition of data; CN has contributed to the conception and the design of the study, and the acquisition of data; KE has contributed to the conception and the design of the study, has been involved in revising the manuscript critically, and has given the final approval for the paper to be published. All authors read and approved the manuscript.

\section{Acknowledgments}

We are grateful to all students who participated in the study, data collectors, and supervisors. We need also to thank CHU Hassan II, and the Faculty of Medicine and Pharmacy of Fez, University Sidi Mohammed Ben Abdallah for funding this study.

\section{Author details}

${ }^{1}$ Laboratory of Epidemiology, Clinical Research, and Health Community, Faculty of Medicine and Pharmacy, Sidi Mohammed Ben Abdallah University, 
Fez, Morocco. ${ }^{2}$ Laboratory of Physiology-Pharmacology and Environmental Health, Dhar El Mahraz Faculty of Sciences, Sidi Mohammed Ben Abdallah University, Fez, Morocco. ${ }^{3}$ Laboratory of Clinical Neurosciences, Faculty of Medicine and Pharmacy, Sidi Mohammed Ben Abdallah University, Fez, Morocco. ${ }^{4}$ Department of Psychiatry, Ibn Al Hassan Hospital, Hassan the 2nd University Hospital Center, Faculty of Medicine and Pharmacy, Sidi Mohammed Ben Abdallah University, Fez, Morocco. ${ }^{5}$ Department of English, Dhar El Mahraz Faculty of literature and human sciences, Sidi Mohammed Ben Abdallah University, Fez, Morocco. ${ }^{6}$ Department of Epidemiology and Public Health, Faculty of Medicine and pharmacy of Fez, Sidi Mohamed Ben Abdillah University, B.P 1893, Route Sidi Harazem, Km 2.2, Fez, Morocco.

Received: 29 June 2015 Accepted: 9 November 2015 Published online: 14 November 2015

\section{References}

1. Silverman MM, Berman AL, Sanddal ND, O'carroll PW, Joiner TE. Rebuilding the tower of Babel: a revised nomenclature for the study of suicide and suicidal behaviors. Part 2: Suicide-related ideations, communications, and behaviors. Suicide Life Threat Behav. 2007; 37(3):264-77.

2. O'Carroll PW, Berman AL, Maris RW, Moscicki EK, Tanney BL, Silverman MM Beyond the Tower of Babel: A nomenclature for suicidology. Suicide Life Threat Behav. 1996;26:237-52

3. Posner K, Oquendo MA, Gould M, Stanley B, Davies M.. Columbia Classification Algorithm of Suicide Assessment (C-CASA): classification of suicidal events in the FDA's pediatric suicidal risk analysis of antidepressants. Am J Psychiatry. 2007;164:1035-43.

4. Bridge JA, Goldstein TR, Brent DA. Adolescent suicide and suicidal behavior. J Child Psychol Psyc. 2006;47(3/4):372-94. doi:10.1111/j.1469-7610.2006.01615.x.

5. Kochanek KD, Xu J, Murphy SL, Minino AM, Kung HC. Deaths: preliminary data for 2009. Nat Vital Stat Report. 2011:59(4):1-51.

6. World Health organization. Preventing suicide: a global imperative. http://www.who.int/mental_health/suicide-prevention/world_report_2014/en/ (2014). Accessed 22 June 2015

7. Karam EG, Hajjar RV, Salamoun MM. Suicidality in the Arab World Part I: Community Studies. Arab J Psychiatry. 2007;18(2):99-107.

8. Agoub M, Moussaoui D, Kadri N. Assessement of suicidality in a Moroccan metropolitan area. J Affect Disord. 2006;90:223-6.

9. World Health organization. Global School-based Student Health Survey: Morocco 2010 Fact Sheet. http://www.who.int/chp/gshs/Morocco_2010_ GSHS_FS.pdf?ua=1 (2010). Accessed 23 June 2015.

10. Lewinsohn PM, Rhode P, Seeley JR. Psychosocial risk factors for future adolescent suicide attempts. J Consult Clin Psychol. 1994;62:297-305.

11. Pelkonen M, Marttunen M. Child and adolescent suicide: epidemiology, risk factors, and approaches to prevention. Paediatric Drugs. 2003;5:243-65.

12. Wu P, Hoven CW, Liu X, Cohen P, Fuller CI, Schaffer D. Substance use, suicidal ideation and attempts in children and adolescents. Suicide Life Threat Behav. 2004:34:408-20.

13. American Psychiatric Association. Diagnostic and Statistical Manual of Mental Disorders. 4th ed. Washington, DC: American Psychiatric Press; 1994

14. Sheehan DV, Lecrubier $Y$, Sheehan $\mathrm{KH}$, Amorim P, Janavs J, Weiller $E$, et al. The Mini-International Neuropsychiatric Interview (M.I.N.I.): the development and validation of a structured diagnostic psychiatric interview for DSM-IV and ICD-10. J Clin Psychiatry. 1998;59 Suppl 20:22-33.

15. Kadri N, Agoub M, EL Gnaoui S, MchichiAlami K, Hergueta T, Moussaoui D. Moroccan Colloquial Arabic version of the Mini-International Neuropsychiatric Interview (M.I.N.I): Qualitative and Quantitative validation. Eur Psychiatry. 2005;20:193-5.

16. El Omari F, Sabir M, Toufiq J. L'usage de drogues auprès des élèves marocains. Enquête Scolaire, Medspad Maroc 2013. http://south-programme-eu.coe.int/ Source/Pompidou_Group/Rapport-etude-MedSPAD-Maroc.pdf. Accessed 18 June 2015

17. Slama K. Tobacco Control and Prevention. A guide for low-income countries. Paris: IUATLD (International union against tuberculosis and lung disease); 1998.

18. World Health organization: Global school-based health survey (GSHS). http://www.who.int/chp/gshs/factsheets/en/ (n.d.). Accessed 22 June 2015.

19. Dervic K, Akkaya-Kalayci T, Kapusta DN, Kaya M, Merl E, Vogel E, et al. Suicidal ideation among Viennese high school students. Wien Klin Wochenschr. 2007;119(5-6):174-80.

20. Liu X, Tein JY, Zhao Z, Sandler IN. Suicidality and correlates among rural adolescents of China. J Adolesc Health. 2005;37(6):443-51.
21. Evans E, Hawton K, Rodham K, Deeks J. The prevalence of suicidal phenomena in adolescents: a systematic review of population-based studies. Suicide Life Threat Behav. 2005;35(3):239-50.

22. Nock MK, Green JG, Hwang I, McLaughlin KA, Sampson NA, Zaslavsky AM, et al. Prevalence, correlates, and treatment of lifetime suicidal behavior among adolescents: results from the National Comorbidity Survey Replication Adolescent Supplement. JAMA Psychiatry. 2013;70:300-10.

23. Carli V, Hoven CW, Wasserman C, Chiesa F, Guffanti G, Sarchiapone M, et al. A newly identified group of adolescents at "invisible" risk for psychopathology and suicidal behavior: findings from the SEYLE study. World Psychiatry. 2014;13:78-86.

24. Baasher TA. Islam and mental health. East Mediterr Health J. 2001;7:372-6.

25. Dew RE, Daniel SS, Armstrong TD, Goldston DB, Triplett MF, Koenig HG. Religion/spirituality and adolescent psychiatric symptoms: a review. Child Psychiatry Hum Dev. 2008;39:381-98.

26. Wong YJ, Rew L, Slaikeu KD. A systematic review of recent research on adolescent religiosity/spirituality and mental health. Issues Ment Health Nurs. 2006;27:161-83.

27. Kann L, Kinchen S, Shanklin SL, Flint KH, Kawkins J, Harris WA, et al. Youth risk behavior surveillance-United States, 2013. MMWR Surveill Summ. 2014;63 Suppl 4:1-168.

28. Shaffer D, Pfeffer CR. Practice parameter for the assessment and treatment of children and adolescents with suicidal behavior. J Am Acad Child Adolesc Psychiatry. 2001;40 Suppl 7:24S-51S.

29. Lewinsohn PM, Rohde P, Seeley JR, Baldwin CL. Gender differences in suicide attempts from adolescence to young adulthood. J Am Acad Child Adolesc Psychiatry. 2001;40:427-34.

30. Rezaeian M. Age and sex suicide rates in the Eastern Mediterranean Region based on global burden of disease estimates for 2000. East Mediterr Health J. 2007;13(4):953-60.

31. Weissman MM, Bland RC, Canino GJ, Greenwald HG, Joyce PR, Karam EG, et al. Prevalence of suicide ideation and suicide attempts in nine countries. Psychol Med. 1999;29:9-17.

32. Canetto SS. She died for love and he for glory: Gender myths of suicidal behavior. Omega: Journal of Death and Dying; 1992-93. v26, n1: 1-17.

33. Canetto SS, Lester D. Gender and the primary prevention of suicide mortality. Suicide Life Threat Behav. 1995;25(1):58-69.

34. Rhodes AE, Boyle MH, Bridge JA, Sinyor M, Links PS, Tonmyr L, et al. Antecedents and sex/gender differences in youth suicidal behavior. World J Psychiatr. 2014;4(4):120-32.

35. Wong SS, Zhou B, Goebert D, Hishinuma ES. The risk of adolescent suicide across patterns of drug use: a nationally representative study of high school students in the United States from 1999 to 2009. Soc Psychiatry Psychiatr Epidemiol. 2013;48(10):1611-20.

36. Yoshimasu K, Kiyohara C, Miyashita K. The Stress Research Group of the Japanese Society for Hygiene. Suicidal risk factors and completed suicide: meta-analyses based on psychological autopsy studies. Environ Health Prev Med. 2008;13(5):243-56.

37. Evren C, Evren B, Bozkurt M. Tobacco use among 10th grade students in Istanbul and related variables. Asian J Psychiatry. 2014;8:69-75.

38. Juan W, Xiao-Juan D, Jia-Ji W, Xin-Wang W, Liang X. The associations between health risk behaviors and suicidal ideation and attempts in an urban Chinese sample of adolescents. J Affect Disord. 2010;126:180-7.

39. Evans E, Hawton K, Rodham K. Factors associated with suicidal phenomena in adolescents: A systematic review of population-based studies. Clin Psychol Rev. 2004:24:957-79.

40. Sher L, Zalsman G. Alcohol and adolescent suicide. Int J Adolesc Med Health. 2005;17:197-203.

41. Pirkola SP, Marttunen MJ, Henriksson MM, Isometsa ET, Heikkinen ME, Lönnqvist JK. Alcohol-related problems among adolescent suicides in Finland. Alcohol Alcohol. 1999:34(3):320-9.

42. Ellickson PL, Martino SC, Collins RL. Marijuana use from adolescence to young adulthood: multiple developmental trajectories and their associated outcomes. Health Psychol. 2004;23:299-307.

43. Hayatbakhsh MR, Najman JM, Jamrozik K, Mamun AA, Alati R, Bor W. Cannabis and anxiety and depression in young adults: a large prospective study. J Am Acad Child Adolesc Psychiatry. 2007:46:408-17.

44. Marmorstein NR, lacono WG. Explaining associations between cannabis use disorders in adolescence and later major depression: a test of the psychosocial failure model. Addict Behav. 2011;36:773-6. 
45. Baumeister RF. Suicide as escape from self. Psychol Rev. 1990;97(1):90-113.

46. Erinoff L, Compton WM, Volkow ND. Drug abuse and suicidal behavior. Drug Alcohol Depend. 2004;76(Suppl):S1-2.

47. Qin P, Agerbo E, Mortensen PB. Suicide risk in relation to socioeconomic, demographic, psychiatric, and familial factors: a national register-based study of all suicides in Denmark, 1981-1997. Am J Psychiatr. 2003;160(4): 765-72.

48. Roberts RE, Chen YR, Roberts CR. Ethnocultural differences in prevalence of adolescent suicidal behaviors. Suicide Life Threat Behav. 1997;27:208-17.

\section{Submit your next manuscript to BioMed Central} and take full advantage of:

- Convenient online submission

- Thorough peer review

- No space constraints or color figure charges

- Immediate publication on acceptance

- Inclusion in PubMed, CAS, Scopus and Google Scholar

- Research which is freely available for redistribution 